Murmurations:

Journal of

Transfórmative

Systemic

Practice

\title{
Creating Dialogical Pop-Up Installations in Public Spaces
}

\author{
Gail Simon, Lisen Kebbe, Ann-Margreth Olsson and Anne \\ Hedvig Vedeler
}

\section{Volume 1}

Issue 1

Winter 2017

\section{Keywords:}

dialogical installation, pop-up space, systemic practice, performance research, qualitative inquiry, writing inquiry, dialogical research

\section{Citation Link}

\section{Abstract}

In this paper, we share reflections from our research into spontaneous coordinations through the creation of pop-up dialogical installations. We offer a collage of anecdotes from our professional practice, from our personal lives and from dialogical installations. These episodes highlight themes from our everyday practice and show us what we do and what we value, but through new doorways. From our work on the streets, we see how i) making something with, and for, people requires daring; ii) we are always involved in reconfiguring dialogical space as we go; iii) we exchange planning for preparation; iv) dialogue is always influenced by, and influencing of, context; v) collage in writing and mixed media allows us to experiment with new configurations of words and share some mo(ve)ments from the installations.

\section{Abstrakt (Swedish)}

I denna artikel, reflekterar vi över tankar från vår forskning inifrån spontana dialogiska förlopp, studerade genom dialogiska pop-up installationer där vi själva deltar. Vi erbjuder ett kollage av anekdoter från våra yrkesverksamheter, från våra personliga liv och från de dialogiska installationerna. Dessa episoder ger nya infallsvinklar och kastar nytt ljus på teman och värderingar i vår dagliga praktik. Genom vårt arbete på gatorna ser vi: i) att det kräver mod att göra något för och med människor; ii) att vi alltid är involverade i att skapa dialogiska rum; iii) hur vi byter ut planering mot förberedelse; iv) att dialoger alltid påverkas av och i sin tur påverkar kontexten; v) att skrivande i collageform och mixed media, gör det möjligt att experimentera med nya former och dela lite av mo(ve)ments från installationerna.

\section{Introduction}

The Måfå Research Group was founded by the four of us upon completing our doctorates in systemic dialogical practice. We experiment with new ways of connecting with people across a range of contexts, learning through the dialogical processes of writing and talking with each other, and others in our worlds. One of our projects has been to create dialogical installations, pop-up spaces, to explore communication - specifically, spontaneous responsivity in moments that matter. 
The works described in this paper were created as part of residencies at the Baltic Art Center on Gotland, the first following our presentations at the $15^{\text {th }}$ International Bakhtin Conference in Stockholm. Our papers were on dialogical activities in therapy, training and organisational consultation. The residency agreement was for us to write up our conference presentations and produce a public event, which gave a new form to our work on dialogical responsivity. The monological culture of the conference on dialogue was striking, and the academy felt divorced from the lives of ordinary people. Our response was to take to the streets, using our knowledge of dialogical practices in experimental forms to see what we could learn.

Our interactive dialogical installations cross social lines. We establish unexpected temporary spaces for chance meetings with passing people in a public place to speak about something important. In one, we invited people to cross an actual line and tell us about a time when they have crossed another sort of line. In another, we simply asked people to come into the space and talk with us. We allow ourselves to engage with people's lives in passing. We reflect on how we create a context for dialogue - wherever we are. We learn to coordinate our way through expected and unexpected moments that inevitably require improvisation. We act as sieve, refractor, translator, host and guest. We are listener, witness, audience, always concerned and anticipatory of the social consequences of our responses.

Participating in these dialogic installations has inevitably involved some relational risk-taking for our surprise guests. They have never failed to captivate us with their daring charm while sharing stories about their lives with us short-lived strangers. And these encounters have required a bold etiquette on our part too, to invite, and listen, and be engaged without a clear brief or set of expectations. But as practitioner-researchers, we work on the edge of space, within or despite certain boundaries. We have less mindfully, and more playfully, used our knowledge of daily practice as surprise-led-coordination-in-the-moment-of-interaction to create a warm space on a cool evening to step over the conceptual lines of relational norms and cultural expectations - some more powerful than others. By creating dialogical opportunities in unexpected places (outside of institutionalised settings) outside the "city walls", our understanding of everyday conversations-as-emergent has enriched our practice elsewhere and produced live interactive installations, videos and papers in progress.

We start by offering you some fragments of meetings woven with reflections on how we make dialogical spaces with people in our everyday lives and in the installations. Then we reflect on some theories that add additional ideas about dialogical space as it forms and re-forms in our work, in installations and in writing this paper. We write as I and We. Sometimes, it may be clear who is speaking, other times not. We write together and separately, from different perspectives and from our own workspaces. The whole is intended to be more than the sum of its parts.

The paper is then a collage of episodes and reflections. As the performance artist, Amy Kilgard says, "It is not the original stories themselves that are most important for this essay. It is their collision." $(2009$, p.1). Choices about juxtaposition are always experimental, and therefore unpredictable in what they may create as a whole or how they are experienced by an audience. So while, as systemic social constructionists, we understand writing as a meaning-making process, we "offer no 'guarantees of meaning'" (Kilgard 2009, p.2). Our invitation to ourselves and readers is to ask,

- What do these stories, together or individually, provoke for you?

- What connections do you make with meetings with people in the different parts of your world?

- Do the stories together make a new whole that is changing of something? 


\section{Walking through a glass wall}

Ten metres from the supermarket entrance, I see two women. One is sitting on a blanket by the main entrance. Her dress makes me think she is Romanian. The other woman is walking from her car to the store, wearing what could be office clothes. She smiles at the woman on the floor and says hello to her as though she knows her. I wonder if they know each other. It seems improbable.

When we get to the supermarket entrance, Lisen holds out her arms in surprise towards this same woman on the blanket. "Helloooo," she bellows and has a big smile on her face. The woman rises off her blanket and they hug and chat about things. Why I am so surprised?

Lisen's greeting was something you rarely see in the UK. People pass over homeless people. They don't stop to talk. They may smile or give money but they don't boom helloooo. It was an engaging, invitational hello. The call brought the woman off her feet. They greeted, it appeared to me, as equals. Standing. Taking up space near the entrance to the supermarket. Lisen said to us, "I will catch up with you". She made time. They made time for each other to talk. I think I was watching to notice if the woman who had been sitting on the blanket felt patronised, or if Lisen was acting in a patronising manner. I couldn't tell. On my flow chart of expectations, a greeting in such circumstances would necessitate an inevitable enactment of power relations. Social corridors have glass walls that assume, and create, an us and a them. But it seemed that, in this moment anyway, Lisen and this woman walked through a glass wall by assuming, and creating, a 'we'.

\section{Setting off together somehow}

"Welcome" I say, showing a new woman into my consulting space. I wave my arm casually towards the sofas and chairs. "Please sit where you feel comfortable". As we sit, I ask, "Are you feeling a little nervous? I am a bit."

When the therapy ends a few months later, the woman tells me how important to her this immediate sharing of vulnerabilities had been. It had, for her, quickly created a "we" and a recognition of an "us" embarking on something together.

\section{Talking in the thick of it}

I am recording an interview in the middle of a train station with people passing and talking nearby. This morning I was in a coffee house, last week a hotel lobby and then a restaurant with the clinking of knives and forks in the background. This month I have been in five family homes, moving between rooms and people and surfaces. I even went to a barracks and sat on dormitory beds to interview someone. Many times, as social worker or researcher, I find that the context for a meeting becomes whatever the client or research participant prefers and invites us into. I am expected to have conversations in the most different, and in the most difficult, of situations.

Watching and listening to the video recordings of the talks in these public and private spaces, I am surprised at how we somehow manage to concentrate on our conversations. I notice how we are listening and responding to the other's responses even when the environment is noisy and distracting. I find myself wondering what is it that makes the difference as to whether we stay engaged or lose concentration? Well, I could think that because the research participants are all 
volunteers, they are well-motivated to contribute. But they are offering their participation and their narratives for free. So, what do they come for? What are they hoping for?

As a researcher, I am keen to listen to their stories, to play a part in witnessing their lives and everyday experiences. So, perhaps we all are ready to give our best in our participation: they, by answering my questions and sharing their stories; me, by listening and asking questions in response to what I hear using the listening questions of the very open and loose interview guide in the research study. As a dialogical researcher, I am always concentrating as much on the relational process as on what is emerging in the present moment of our talk. Participants, on the other hand, seem to travel between the present, the past, and ideas about the future prompted by my questions. Our surroundings feel incidental.

\section{Co-constructing as improvising}

We survey our surroundings, we point to trees and lampposts, indicating how they could play a part in creating a stage. We are hoping to generate a wall-less room, a safe but risky space where the risk comes from imagining that it will be safe enough to step over the line and pass into a soon-to-be jointly imagined space which we host, in which the other allows themselves to be welcomed. Yet we are not staging anything. There is no platform. We are not putting on a performance for others. This is not an us-and-them thing.

There is something about just turning up with a bag of goods - paper bags, a wide reel of tape with the word C A U T I O N writ large in black on yellow. A reel of red cinema tickets. A wide ball of green string. Several large Scandinavian floor candles that could set your turn-ups alight if you weren't careful. Old velvet curtains, star-shaped post-it notes, pens, a knife. A shopping bag filled with smooth and rounded stones from the beach just a pebble's throw away. Tipping all this out onto the dry summer grass, we look around and imagine how they will work together to create a space. Not just any space but one that invites conversation, which evokes dialogue.

And here Ann-Margreth says, "Well you say dialogue. But my experience was that some of us," and she pauses so we have time to anticipate ourselves in the next part of the sentence, "plan in such a way that the process between us is monological." And then Lisen says, "Yes, but...". And so, we are also among the many things we tip out onto the short yellow grass. We all privately hope for more gracefulness in the dialogical installation than we can at times manage between ourselves.

\section{Preparation, not planning}

Breakfast turns into a planning meeting for the coming pop up event. However, not all of us show the same interest in this planning. In the end, Lisen suggests using the ideas of Open Space and putting up our ideas on a wall, and that we re-convene at midday. Anne Hedvig goes out to buy a toothbrush and I take some time enjoying the morning sun. When I come back, Gail and Lisen have already started planning. I listen and observe their collaboration. A yellow band with warning-text usually used by American police, I think, and a whole spool of old-style cinema tickets are the main focus. They discuss how we can invite people into dialogue in a space bounded by this yellow tape, carpeted with some old velvet curtains and somehow use the tickets for people to ride into the space. 
By the time Anne Hedvig arrives back, Lisen and Gail already have a plan. Anne Hedvig listens, and then she says, "Dialogue is about being spontaneously responsive - what impact will all these instructions have?"

I agree with her. "Isn't a pop-up event enough when a dialogue emerges in a meeting?" I ask. "Do we really need to make such detailed and planned arrangements for these chance meetings? What is it that makes it easier for dialogical interplay to emerge with or without these props? When might some of these plans even prevent or obstruct dialogue?"

John Shotter warned about the limiting effect of planning but spoke about preparation as a preferred state of being. We need to remember that, "we are not wholly 'at sea without a compass', as it might at first sight seem. In giving up our search for ideal forms, and in being prepared to begin with our sensings, with the distinctive movements of feeling occurring within us as we experience the particular situation currently confronting us, we find ourselves with a quite different set of questions, relating to a quite different set of 'background' understandings." (Shotter 2016, p.122)

For our inquiry into creating dialogical spaces, we would also need to use our sense-able selves in the imagined space with our as yet unknown dialogical partners. During our residencies at the Baltic Arts Center on Gotland, the challenge of preparation for dialogue became the grand overarching theme in our group discussions.

In addition to the bag of things and ourselves, we have two questions:

"Do you have a story to tell of when you crossed a line?"

"How did you find the courage to cross that line?"

\section{Greetings as meetings}

Our problems become possibilities. We worry about interfering with thoroughfares and discuss the etiquette in approaching people walking by our make-believe room. We become the surrounds, the fluid imperfect boundaries, living conduits pointing to, guiding in, stepping away. We open paths that come into being simply by lifting our arms. We are forming new systems by creating new spaces - a state of perpetual re-structuring as we approach, engage and withdraw from passers-by. We feel their hesitation mirroring ours - a symmetrical coordination of careful movements. We breathe in and on the out breath, move in words or looks or paces towards them with a question, a reflection. Sometimes it is one difference that makes a difference (we are not sure which difference makes what difference) and people are drawn, changing their direction, their pace, their receptivity towards this ground-level, sunlit space we have made. Sometimes we are waved away with blank eyes. We are weaving tensions of playfulness as attractors with honouring those whose stories we are hearing. Our presence in the conversations has a soft urgency, in that each of us is listening and responding with our whole body. Out breaths of awe or laughter. In breaths of curiosity or shock. Frozen seconds of indecision and not knowing how to react melting into compassion, recognition, appreciation.

At times, we have wondered how we can invite visitors to feel a shared ownership of the space (this space, the space, a space, their space, our space, this jointly held/hosted/offered/created space), to take hold of it and shape it. It makes sense to us now that when people are met with respect and welcomed into conversation, they wish to return the respect and are, in any case, lost in the cocoon of conversation surrounded by accoutrements that become simply a supporting backdrop for other 
vistas not immediately visible to others outside of those situations. The flames of the candles glance this way and that, as if shadowing the speakers. The wafting tape whose message has been ignored, no, deliberately transgressed, in order to enter this space, struggles for attention. The speakers now in silhouette are in their own world, re-built word by word, glance by glance, eye movement and breaths, moving noises not always making it into intelligible words, totally intelligible to the other. And the sea acts as a natural boundary along one edge. A reminder that we are bound not to go too far out of anyone's depth. And we trust people to know this and guide us. We are careful movers, not shakers. People appear to shake themselves free in these tellings. And clutching their tickets, now precious red against their white clothes, speak with eyes alight and words streaming as if on a static free channel. And we are mesmerised. Captive in our own space, unable to move or control our breathing. Their caution-free words undo us and we are taken aback by their eloquence and daring.

\section{Daring in deed, daring in dialogue (and dialogue as deed)}

Two little girls - one about eleven years old, the other nine - are dressed in t-shirts and shorts. When they take a red ticket from one of us, they look puzzled but also curious. I explain that the ticket can be used to step over the yellow ribbon of CAUTION and come in to this space and talk with me about times when they have done things that cross a line that is normally forbidden. The girls look at each other to check each other's judgement about this invitation. They look at Gail who gave them the ticket, they look at me in my medieval smock and pinafore, then they turn around to look for their parents who have caught up with them. The parents, a woman and a man, nod and say they are okay, meaning us. The children quickly step over the tape of CAUTION into the space while the parents seat themselves on the bench and chat with Gail.

Standing on the velvet curtains that form the floor of our "room", the girls start talking without any prompt.

"When you are a child," says the older girl, "you have to do exciting and forbidden things."

"When you are small." says the younger.

"Yes, you need to have some memories for when you are older, so you have something to say in the future when you have your own children."

"Because then it's over, grownups never do anything forbidden or exciting things," adds the younger girl.

"Do you collect any stories about doing these things then?" I ask. "You could write them down, and be a writer like Astrid Lindgren?"

"Yes, we do, we do." they said nodding furiously, eyes wide open.

"I write them down." said the older girl. "I have written two hundred stories in notebooks that I stapled together myself."

"What's the most exciting thing about doing forbidden things?" I ask them.

They confer a little about their past experiences and then the older one says:

"It is as exciting when you plan to do something that is forbidden as it is when you think about it afterwards. But it is most exciting while you are doing it." 


\section{Light markers}

From the curved bench facing the sea, the sunset turns from orange to crimson and takes with it the day. We are in a crepuscular time and space. The light is diminishing and the flames of the candles are more visible. Lisen has become a silhouette.

And still there are those evening walkers who stop, allow themselves to be engaged and "step over the line" into this dialogical space along the promenade which traces the medieval city wall of Visby by the bronze sea. The evening strollers pause. You can almost hear them wonder, "Are we allowed to ignore the message on the ribbon, 'Caution. Do not cross the line'?" and act instead in response to the spoken invitation to transgress the written word and cross this line. Some appear to suspend their breathing as they step over the authoritative yellow band with its warning-text, a border to be crossed to allow access this special zone (that we made - borders are always synthetic) to where Lisen stands, open, ready to be engaged and engaging in dialogue. At times she says Aha! and Yes! and $\mathrm{Oh}$ ! and writes down important words they say about what it means to cross the line. She writes them on the bright star-shaped shop tags we have hanging from the railings along the sea edge. Lisen looks impressive in her hat and long medieval costume. And as the sun sinks behind the edge of the blackening sea, the light of the candles re-mark the boundary of the space. From a distance, one family told me, it looked like a private area where something ceremonial was going on.

\section{A silhouette with two faces in dialogue with each other}

A young woman aged eighteen tells Lisen aged sixty, "It's important to know your own limits - to be true to yourself, and not to let yourself be pushed over that limit by others. But it's also important to know when you are just being cowardly because that can hold you back."

\section{Breaking the sound barrier}

For a while now, a young man of about nineteen and a young woman of about eighteen have been sitting tightly side by side on the curved bench facing the sea, holding hands. They shake their heads when asked if they want to cross the line but they take a red ticket each and one of them says quietly to Ann-Margreth that they have crossed a line. Ann-Margreth asks them something but they answer in monosyllables. She turns away to give them privacy and speaks instead with others passing along the front. They sit for quite a while, speaking quietly with each other. After a while, I go to sit down and find the bench vacated. "Look," says Ann-Margreth. The young couple are talking with Lisen.

They tell her they have been together for nine months, their families don't approve of their relationship but they are pursuing it anyway.

"You have to cross the line to get anywhere. We have both broken the shyness barrier, that's how we got together." says the young woman.

The young man volunteers, "Now we are facing another line we need to get over."

Lisen asks them something. They look away. They don't want to talk about that.

"But we are going to get over it." says the young man. 
And the young woman continues, "It's a line that we don't really want to talk about, but we do talk about it just the same. We SHALL get over it!"

And he nods.

\section{Shaping space as sharing and evolving}

Our first dialogical pop-up space was self-invitational. Open for wandering into. We chose a place at the edge of the town along the sea front, where people walk in the evenings. Three boys on skateboards, maybe 14 years old, were making crazy runs and doing somersaults high into the air over concrete and grass along the edge of the space we were setting up. After a few minutes of us laying out white paper bags, placing candles with a few sea-washed pebbles in each, the boys came away from their acrobatics to ask us what we were doing. We explained we were creating a space for people to walk in and reflect on their lives. They asked if they could help construct the space. This was a pivotal moment. The space was no longer an enterprise by four of us. It became a community effort.

The bags were far enough apart to wander between but close enough together for the parts to create a whole, projecting a collective glow. The installation was demarcated by the limit of its luminosity where darkness took over and seeing was replaced by hearing the soft breaking of waves invisible in the dark.

This space spoke for itself. We were only partly visible, mingling, sometimes with low-key questions and responses. Many people wandered through. They sometimes asked why it was there or who had made it. It seemed to invite participants to walk between and look into the glimmering bags. People started up conversations with other visitors or with us.

\section{Explain this to me}

A young man in his 20 s with a can of beer in his hand is walking towards me.

"Explain this to me." he says.

"Sure," I respond, "It's a room that you can walk into and around."

"Okay."

"It's a room where we can talk to each other, a dialogical room." I pause. He is looking around it, thinking.

"A dialogical room?"

"Yes. What do you think it looks like?

"I like it when things have to do with culture. Does this have to do with the culture on Gotland?"

"You tell us. When you look into the bags with the candles and stones, what do you see that is to do with Gotland?"

He starts to look and then pulls back. His gaze moves from the bags to somewhere out of our sight in the middle distance. Suddenly he turns to me. 
"Is this a way of gathering tourists to earn money?"

"No," I answer. And I am struck by the gulf between local people and tourists and how money separates people. People don't expect to be considered worthy of attention unless they have money.

"No, but is it something real, something that has to do with Gotland?"

"Well, it has to do with human experience, whether you live on Gotland or not."

"Yes, but it is something you have made up or...?"

"Yes, we made it up. Do you know what we thought? We thought we want this to be like a room with all these bags with light and things in them, a dialogic room. We wanted to invite people to stay in here and talk to each other exactly like you and I are doing now."

"That's great, I think that is really great!"

"That's it. Then you can interpret it in the way you like."

"I really like this."

"Uhuh?"

"It's good that you invent things to make people come together."

"Exactly."

"I think it's a really good idea that you don't make profit from anybody by this idea."

"No, we don't want to attract you to make money out of you. Just talk with you."

"No, you just attract people because you want them to come here."

"Nothing else, that's the way it is."

"I think this is a super good idea."

"That's good."

He lifts his beer can and offers me a sip.

"No, thank you."

"Don't you drink alcohol?"

"Well, I have some cool drink. Do you want some?"

"Yes, thanks."

And he tells us how he has been looking everywhere for a friend who has problems. He looks worried. He describes him to us and asks that we tell him to go home if we see him.

\section{Creating passers-by and watchers}

When the crowds faded late in the evening, we moved the bags into a long line along the sea wall where they stood in a bold straight flickering line protesting a solitary, monological stance. 


\section{Disintegration as part of transformation of dialogical space}

Later, when we got tired of watching, or maybe wanted to go and eat, we moved them bag by bag to the sea edge, made another line this time close to the black Baltic water. One of us set fire to the bag nearest the pier. They burned slowly, contiguously, systematically and idiosyncratically. None of us spoke. The fire crackled as it picked up and made its way, slowly joining each of the single bags into unpredictable relations. The sea a constant, invisibly reshaping the edge of the land with its teasing of the pebbles.

A boy appeared out of the darkness. Sixteen, perhaps. I don't know for sure as I couldn't see him from where I was filming this, and I didn't look up so I could keep the camera steady. He sat above us on the sea wall, lit from behind by a distant street light. "Hei!" he called. "Har du en cigarett?" Despite us not having cigarettes, he stayed and asked questions. What are you doing that for? Is it allowed to set fire to things in public places? It's cool, he said. His voice fell silent. It was as if he found peace being with us, staring at the fire as it travelled in its own unhurried time.

The line was burning itself up leaving a trail of flickering red embers standing still, falling, curling, constantly surprising the onlooker schooled in the expectation of speed. The queue of paper bags was not going so much as changing. A new space emerged around this unpredictable procession of light and noise and smoke. The paper bags, once containers for calm candles illuminating the visions of the visitors, were regenerating, becoming the flames themselves, illuminating their own metamorphosis: light - embers - ash. Perpetual motion and transformation. Like the sea, a metre away. So different from the sea, a metre away.

Another voice entered the scene. "Hej du!" It was the voice of a man. "Helvete..." muttered the boy and didn't move. I sensed the others look up. The man had something to say to the boy. I was not sure what the relationship between them was. He could have been the boy's care worker or his pimp. I was alarmed that I couldn't work out which it was but I could see, from how Ann-Margreth and Lisen were as an audience to this conversation, that they were concerned but not worried. The boy reluctantly got himself up off the stone wall overlooking our fire at the edge of the black sea night, disappeared into the shadows with the man and we stayed silent as their voices got fainter until they disappeared. It was just us again. We didn't speak. The sea creeping round the stones had a quiet urgency. It seemed like a very long time that we stood there in the darkness observing the line of fire lie itself down, merging with the pebbles that coat the Baltic basin until the blackness took over. A few embers continued to live, animating our memory of what had been. Some glowed themselves into a steady death. Some appeared to die and then winked at us as if to challenge our assumption that everything is finite.

\section{Dialogical space as a performance of possibilities}

"The performance of possibilities centers on the principles of transformation and transgression, dialogue and interrogation, as well as acceptance and imagination to build worlds that are possible."

(Madison 2003, p.472)

These dialogical installations involved the construction of a space of possibilities - space without finalised ideas of outcome for us and, or for, others. This was not a method-led exercise with a clearly anticipated route, marked by procedures, and without unscheduled stops or detours. Anne 
Hedvig's and Ann-Margreth's concern that too much pre-existing structure would limit the possibilities in mutually generative space, echoes something in Victor Turner's comment that, "Cognitive reductionism has always struck me as a kind of dehydration of social life." (1979, p.82).

Our decision to prepare and not plan (too much) was an ethical stance familiar in systemic practice. We needed to create enough room for ourselves to interact with the limits and possibilities of the physical space. We also needed to make room for participants to shape the experience. We were acting and inquiring beyond method (Lather 2013; Lather \& St Pierre 2013) and as Alicia Jackson (2017) says, thinking without method. "Thinking without method relieves qualitative inquiry from the twin forms of epistemological imperatives of knowledge production and a conventional dependency on procedural method. Freedom from this reliance gives us a new starting place: the outside of method." (Jackson 2017). Dialogical ways of being defy boundaries created and imposed by one party on others. As John Shotter has said, "one is learning how to improvise rather than trying to follow any rules or recipes" (Shotter 2008).

We can understand all performers in these dialogical installations as not only being engaged but striving to become (Madison 2003, p.480). This becoming is not a finite process where one can expect to arrive at some complete knowledge, or be able to reproduce a story as if it is a whole and watertight episode. Nor can becoming result in arriving at a final way of being. In a social world, becoming can be seen as a multi-routing, parallel and criss-crossing, short and long strands of leads we are exploring, following, and making as responses to our changing environments. Renditions of these chaotic processes can only be partial, subjective and incomplete tellings, and trouble existing ways of knowing and being.

We became transfixed by the story of the other, moving from a position of mild curiosity and readiness to be arrested by the visitor's story. Suspended in awe of the teller, unsettled by their thoughtful rendition of a daring episode, taken aback by their daring in telling us how they became who they are now, how they were preparing for another change in their lives. Quite unexpectedly, we lost positions of insider and outsider and quickly became guests in each other's worlds. We were carried by their stories, moved by their demeanour. We are changed now by their gifts of openness, sharing knowledge and narratives of bravery, uncertainty, their efforts to free themselves of constraints in their lives. People we didn't know stepped over a line into our demarcated space and we, in turn, without planning or realising it, stepped over a line towards them, by invitation, into their worlds; our listening, our spontaneous expressive responses like an outstretched hand saying I am with you for now, I am following you. Yet we were in a most public space. And asking the same questions as Ann-Margreth with her conversations with people about intimate matters in public spaces. How can we manage to be so involved and so quickly with people we didn't know five minutes ago? How come people are prepared to open up aspects of their lives and thoughts to strangers? A certain quality of dialogical space allows us to travel in moving detail between worlds and 'problematize how we categorize who is 'us' and who is 'them', and how we see ourselves with 'other' and different eyes" (Madison 2003, p.478). The enclosed space in a public thoroughfare brings "the domains of outside and insider are simultaneously demarcated and fused" (Madison 2003, p.478). The location and light allows the participants to be seen engaged with each other creating a single dialogue but starkly outlined against the horizon as individual people.

Conquergood (2002a) refers to Gloria Anzaldúa's comment that "the future depends on the breaking down of paradigms, it depends on the straddling of two or more cultures" $(1987, p .80)$. Distinctions between disciplinary spaces have been built, braced, blurred and broken over time, relying on transgression and disturbance to adapt to contextual need. The tension between preparing space 
and spontaneous dialogue is found in organisational consultancy, psychotherapy, teaching, academic or professional supervision, architecture, and so on. "The dialogical stance is situated in the space between competing ideologies. It brings self and Other together even while it holds them apart. It is more like a hyphen than a period" (Conquergood, 2003, p. 408). In these dialogical installations, we displace the systemic practices of dialogue and relational sensibilities to use them over slippery hyphens in multidisciplinary space with performance, art installation, philosophy, critical theory and qualitative research.

"In a performance of possibilities, I see the 'possible' as suggesting a movement culminating in creation and change. It is the active, creative work that weaves the life of the mind with being mindful of life, of 'merging text and world', of critically traversing the margin and the center, and of opening more and different paths for enlivening relations and spaces."

(Madison 2003, p.471).

When writing now, in this moment of social and political instability in and between many countries across our world, there is perhaps additional reason to consider how we might step over a line, overcome caution, to speak with those who think differently about the world to us. And imagine how we can achieve a similar genuine willingness to be ready to see the world through the eyes of others, and understand their caution in seeing the world in the way we might.

\section{Teaming with ideas: coordination and clumsiness at carnival}

"Artistic form, correctly understood, does not shape already prepared and found content, but rather permits content to be found and seen for the first time"

(Bakhtin 1984, p.43).

Our writings are also performative. They are stories told mindfully yet in the dark to an imagined audience. They intend to describe from within the acts of doing or reflection, using tense to take the reader back in time or into the present moment of interaction or reflection. We speak as 'we' in places where theory allows us an aboutness position (Shotter 1999), space to reflect in, and on, dialogue with the writings of others (Simon 2012) and as "I" from within the liveness of activity (Shotter 1999).

Team working was experimental and the activities in some ways parodying of our responsible professional selves by employing our professional know-how in an ad hoc dialogical space (Bakhtin 1968). Parody allows participants to resituate themselves within hierarchies of power and render common practice uncommon by taking it into alternative contexts.

In one of the dialogical pop-up spaces, Lisen was dressed like other local people for the annual medieval week. We spontaneously picked up some hats from a jazz quartet led by Lisen's daughter. Perhaps we also dress 'up' in our professional work. The red theatre tickets were a wild card which added a theatrical lead in to our approaches to passers-by. We played at inviting people into a room, carpeted by once rich old velvet curtains now walked over in a dusty place. Our normal caution in inviting people into spaces was replaced by playfulness alongside care. Unlike the therapy room, 
where people often privately overcome caution to in order to enter, we rendered visible that caution and playfully induced them to step over a line of tape advising people to be cautious.

The tensions in negotiating the dialogical installations often addressed playfulness, and collaboration in our preparation at times was often about what counted as going too far. Too far might be in relation to the ethics or practicalities in planning and creating dialogical space or safety, in terms of fire or personal choice. For example, we echoed what the two young girls had described when they spoke of the excitement in planning forbidden activities and their excitement when doing them.

Researcher 1: "When you raised that concern about what was allowed or not in a public space, it made me all the more keen to do it anyway."

Researcher 2: "Me too. It was exciting to see what would happen."

Researcher 3: "This is where we see the difference between dialogical collaboration and monological planning."

Researcher 4: “Or perhaps connect with Bakhtin's notion of carnival in which people take ownership of the streets to parody those in power?"

Researcher 2: "To parody normative practices of where meaningful dialogue is expected to take place."

In taking different positions at different times, we built a culture of group reflexivity and developed a shared mind. Mind, here, being the fluid, reflexive, formative activities going on between people. Perhaps it echoes Fleck's idea of thought collective:

"What if, for instance, that which in our everyday talk we call the exercise of 'wisdom' and 'judgement' has little to do with the exercise of a capacity or a disposition already in existence within an individual, but is much more to do with a process of innovation, improvisation, or creative emergence occurring within the activities of an individual within the context of what Fleck (1979) calls a 'thought collective' - a social group with a shared culture and history, a professional group with shared standards of performance, a group of scientists with a shared project?"

(Shotter 2008).

The writing of this paper has relied on collaboration, imagining and consulting others, and we have managed eloquence and gracefulness in parts, but also it has been a clumsier process. It has involved stumbling around, at times chaotically, and yet this has seemed necessary to a productive outcome. Apparently, there are recommended methods for good (meaning, efficient) team working on joint papers. They involve planning in advance, negotiation, and clarity concerning roles and timeframes. The process was not like that for us. But woven through the process of writing this paper was also an inevitable process of reflection and meaning-making for us. It was never simply reporting on something. It has been a form of making and re-making accounts of collaborative practice. We did not always agree on what had taken place, or why, or with what result. Perhaps it has been closer to how a "transformation of points of struggle into points of insight is a coexperienced moment of shared epistemology" (Sommerfeldt et al 2014). 
Sommerfeldt (2014) remarks that the "team work is relative, relational, and temporal, a rather unstable and changeable component of being a team" but we are inclined toward the notion that team work is not separate from team. Rather it creates team, and is a form of fluid roles and responsibilities moving in relation to where there is space and need. In this sense, one can understand team as team-working and as a form of dynamic stability allowing for movements between people, shifts in influence, with changes in leaders and followers, requiring coordinations and synchronous skill for managing of clumsiness and difference.

The process of assembling this paper has reflected some of the risk and adventure we experienced in staging the scene for the dialogical pop-up spaces. We had materials but we didn't have a plan of how they might work together until we tried them in situ. And we didn't know where we would choose to place ourselves until we went, as a group and looked around, tried somewhere, then packed up to move to a safer and more practical site. We did not know which stories each of us was going to write for this paper, nor the roles we were going to play in its creation - although the roles we play were familiar to us when they happened. We did not know what we were really going to do with people in the pop-up space, nor how they or we would respond but we knew what to do in the moment. Our roles were distinct and, looking back, predictable to some degree. Nevertheless, all episodes, both in the dialogical spaces of the installations or within this paper, have felt as if they were happening for the first time as if "once-occurrent events of Being" (Bakhtin 1993, p.1). This edginess reflected the adventure and risk Kilgard describes as inevitable when assembling collage. She explains how juxtaposing and assembling narrative fragments into a whole involves an element of adventure. "This additional component of risk is something I often find in performative juxtapositions, in, for example, a leap across the stage edge." (Kilgard 2009, p.2).

\section{Closing thoughts}

It has been and continues to be moving for us to speak with people whether in dialogical pop-up spaces, in therapy, consultation, supervision or research, or indeed in our personal worlds. All participants are changed to varying degrees by these encounters. Getting involved so quickly with people, taking risks with people is all very personal. It involves a tearing down of old narratives of personal and professional for light and air to come into the spaces we build with people in everyday dialogue (Kebbe 2011). We draw on our professional trainings and body of knowledge to reflect on what is happening between people, what we can co-create in ways which are spontaneously responsive and unique to each encounter.

Developing a written account from fragments which recognised our different personal and professional perspectives and experience made for a richer account and new learning for each of us. Writing, reading and reflecting both on the material and on each other's reflections, have played a significant part in our inquiry (Kebbe 2014; Richardson 1994; Simon 2012). New punctuations of joint activities in the dialogical pop-up spaces brought new punctuations of our professional activities.

Madison points out that "the performance of possibilities centers on the principles of transformation and transgression, dialogue and interrogation, as well as acceptance and imagination to build worlds that are possible" (2003, p.472). We are reminded through these experimental activities and experimental ways of writing about them, that we experiment all day, every day. These pop-up relationship-building skills rely on a kind of careful and strategic irreverence for how we meet and greet people, so we can open up opportunities to perform new selves, speak about possibilities, and find new learning through story-telling and story-sharing. 


\section{Acknowledgements}

Our appreciation to the Baltic Art Center, Gotland for their support of this work and to the reviewers who helped make this a stronger paper.

\section{References}

Anzaldúa, Gloria (1987). Borderlands/La Frontera: The New Mestiza. San Francisco: Spinsters/Aunt Lute.

Bakhtin, Mikhail M. (1968). Rabelais and His World. Translation by Helene Iswolsky. Cambridge, MA: MIT Press.

Bakhtin, Mikhail M. (1984). Problems of Dostoevskýs Poetics. Edited and trans. by Caryl Emerson. Minneapolis: University of Minnesota Press.

Bakhtin, Mikhail M. (1993). Toward a Philosophy of the Act. Translation and notes by Vadim Lianpov, edited by Michael Holquist. Austin, TX: University of Texas Press.

Conquergood, Dwight (2002a). Of Caravans and Carnivals: Performance Studies in Motion. The Drama Review, $39,4,137-141$.

Conquergood, Dwight (2002b). Performance Studies. Interventions and Radical Research. The Drama Review, $46,2,145-156$.

Conquergood. Dwight (2003). Performing as a moral act: Ethical dimensions of the ethnography of performance. In Y. Lincoln \& N. Denzin (Eds.), Turning points in qualitative research. 397-413. New York: AltaMira Press.

Jackson, Alicia Youngblood (2017). Thinking Without Method. Qualitative Inquiry, xxxxx, 1-9.

https://doi.org/10.1177/1077800417725355

Kebbe, Lisen (2011). Keep the conversation going: a study of conversational spaces during family business succession. Unpublished doctoral thesis. http://hdl.handle.net/10547/234472

Kebbe, Lisen (2014). Essay writing as a method of inquiry. Systemic Inquiry. Innovations in reflexive practice research. Farnhill: Everything is Connected Press.

Kilgard, Amy K. (2009). Collage: A Paradigm for Performance Studies. Liminalities: A Journal of Performance Studies, 5, 3, 1-19.

Lather, Patti (2013). Methodology-21: What do we do in the afterward? International Journal of Qualitative Studies in Education, 26, 6, 634-645. https://doi.org/10.1080/09518398.2013.788753

Lather, Patti \& St. Pierre, Elizabeth (2013). Post-qualitative research. International Journal of Qualitative Studies in Education, 26, 6, 629-633. https://doi.org/10.1080/09518398.2013.788752

Madison, D. Soyini (2003). Performance, Personal Narratives, and the Politics of Possibility. In Turning Points in Qualitative Research: Tying Knots in a Handkerchief edited by Yvonna S. Lincoln, Norman K. Denzin, Walnut Creek, CA: AltaMira Press.

Richardson, Laurel (1994). Writing: A method of inquiry. In Norman K. Denzin \& Yvonna S. Lincoln (Eds.), The SAGE handbook of qualitative research (pp.516-529). London: Sage.

Shotter, John (1989). Social accountability and the social construction of "you". In Kenneth Gergen \& John Shotter (Eds.), Texts of Identity (pp.133-151). London: Sage. 
Shotter, John (1999). Writing from within "living moments": "Withness-writing" rather than "aboutnesswriting". Fourth National Writing Across the Curriculum Conference: Multiple Intelligences, Cornell University, June 3-5, 1999.

Shotter, John (2008). Notes on Acting from within a "Thought Collective" (Fleck, 1979) - Moving on from 'after the fact' thinking to 'before the fact' thinking. www.johnshotter.com

Shotter, John (2011). Getting it: With-ness thinking and the dialogical ... in practice. London: Hampton Press.

Shotter, John (2016). Speaking, Actually: Towards a New 'Fluid' Common-Sense Understanding of Relational Becomings. Farnhill: Everything is Connected Press.

Simon, Gail (2012). Relational Ethnography: Writing and Reading in Research Relationships. Forum Qualitative Sozialforschung / Forum: Qualitative Social Research, 14, 1, Art. 4, http://nbn-resolving.de/urn:nbn:de:0114fqs130147.

Sommerfeldt, Susan C.; Caine, Vera \& Molzahn, Anita (2014). Considering Performativity as Methodology and Phenomena. Forum Qualitative Sozialforschung / Forum: Qualitative Social Research, 15,2, Art. 11, http://nbn-resolving.de/urn:nbn:de:0114-fqs1402112

Turner, Victor (1979). Dramatic Ritual/Ritual Drama: Performative and Reflexive Anthropology. The Kenyon Review, New Series, 1, 3, 80-93.

\section{Authors}

Gail Simon is Programme Director for the Professional Doctorate in Systemic Practice at the University of Bedfordshire and runs writing groups for reflexive practitioners. Gail co-founded The Pink Practice in London, UK, which pioneered systemic social constructionist therapy for the lesbian, gay and queer communities. She has edited books on systemic practice and research and is editor of Murmurations: Journal of Transformative Systemic Practice.

Gail Simon, University of Bedfordshire, University Square, Luton, LU1 3JU.

E-mail: gail.simon@beds.ac.uk

URL: https://beds.academia.edu/GailSimon

Lisen Kebbe is a Psychologist with her own private practice offering therapy with individuals and families. Lisen uses a collaborative approach with families and young people in severe social and psychiatric crisis. Lisen is passionately involved in developing new ways of evolving dialogical and listening cultures in working groups. Her doctoral thesis "Keep the conversation going" is an in-depth study of her work with a transgenerational succession process with a farming family.

Lisen Kebbe, Mellangatan 40, 62156 Visby, Sweden.

Email: lisen@kebbe.se

URL: www.kebbe.se

Ann-Margreth E. Olsson is a Senior Lecturer in Social Work at Kristianstad University. Her publications arise out of her primary fields of research in social work, children's participation, child welfare investigations, Barnahus (residential care for children), military families (soldiers, veterans and their extended families), and systemic and dialogical coaching and supervision.

Ann-Margreth Olsson, Kristianstad University, SE-291 88 Kristianstad, Sweden.

E-mail: ann-margreth.olsson@hkr.se / a@amove.se

URL: http://www.amove.se/ 
Anne Hedvig Vedeler is an assistant professor at VID Specialized University in Oslo, Norway, where she is the director of the Personal and Professional Program. She has her own private practice called Dialogical Practice, offering therapy, consultation, coaching, supervision, and teaching. Her publications reflect her commitment to dialogical supervision. Her doctoral thesis, "Diving into the Poetic Movements" explore this way of relating to the world as an open place.

Anne Hedvig Helmer Vedeler, Terrassestien 14, 1459, Nesodden, Norway.

Email: annehedvig.vedeler@vid.no

URL: mafaresearch.com

\section{Citation}

Simon, Gail; Kebbe, Lisen; Olsson, Ann-Margreth \& Vedeler, Anne Hedvig (2017). Creating Dialogical Pop-Up Installations in Public Spaces. Murmurations: Journal of Transformative Systemic Practice, 1 (1), 1-17.

https://doi.org/10.28963/1.1.2 